Artigo recebido em

29/07/2014

Aprovado em

$27 / 10 / 2014$

REGINA

CAZZAMATTA

Universität Erfurt Alemanha

Bacharelado em jornalismo e pósgraduação em Jornalismo Internacional pela PUCSP. Mestre em Ciências da Comunicação e doutoranda pela Uni Erfurt. Autora do livro "Brasilien-

Berichterstattung in der deutschen Presse".

Pesquisa atualmente a imagem da América Latina na mídia alemã.
Estudos em Jornalismo e Mídia

Vol. 11 No 2

Julho a Dezembro de 2014

ISSNe 1984-6924

\section{A imagem do Brasil na imprensa alemã: um estudo empírico sobre os fatores de seleção da notícia e da estrutura do noticiário}

\author{
Regina Cazzamatta
}

\section{Resumo}

Este artigo apresenta um resumo não só da perspectiva teórica, como também dos resultados empíricos publicados recentemente em Brasilienberichterstattung in der deutschen Presse (Cazzamatta, 2014). A análise foi composta por 431 textos ao longo de três anos (2010-2012) produzidos pelos seguintes veículos da mídia impressa alemã: os jornais Süddeutsche Zeitung, Frankfurter Allgemeine Zeitung, Die Welt e tageszeitung; além dos semanários Der Spiegel, Focus, Die Zeit e Stern. A primeira etapa da pesquisa conduziu uma análise de conteúdo quantitativa para reconstruir a estrutura do noticiário, seus temas e fontes, de acordo com as teorias de seleção da notícia de tradição europeia. Em um segundo nível de análise, procurou-se identificar de forma qualitativa os frames discursivos dos temas mais recorrentes.

Palavras-chave

Nações, News Value, Gatekeeper, Etnocentrismo, Estrutura do noticiário.

\begin{abstract}
This article presents a summary from both the theoretical perspective and the empirical results published recently in Brasilien Berichterstattung in der deutschen Presse (Cazzamatta, 2014). The analysis consists of 431 texts published over three years (2010-2012) by the following German press: the newspapers Süddeutsche Zeitung, Frankfurter Allgemeine Zeitung, Die Welt, tageszeitung; in addition to the weekly magazines Der Spiegel, Focus, Die Zeit e Stern. The first stage of the research conducted a quantitative content analysis to reconstruct the structure of the news coverage of Brazil, its themes and sources, according to the theories of news selection (News Values and Gatekeeper) from the European tradition. On a second level, the research attempts to identify through qualitative content analyses the mains frames of the most frequent themes.
\end{abstract}

Keywords

Brazilian Image, German Press, News Value, Gatekeeper, Ethnocentrisms. 


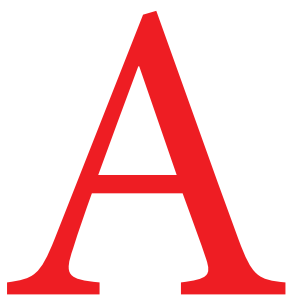

mídia tem um papel determinante na propagação de informação e conhecimento sobre outras nações. É através da seleção, apresentação e representação dos conteúdos que a mídia influencia a realidade do receptor, principalmente onde falta a chamada experiência primária. "Quanto maior a distância geográfica e a complexidade de um fato, maior é a dificuldade de compreender tal acontecimento fora do alcance de nossas experiências". (Schenk, 1987, p. 36). Além disso, a grande maioria das pessoas, que não possui a oportunidade de vivenciar e observar processos e desenvolvimentos em um país estrangeiro, depende da grande mídia para criar uma ideia ou imagem desses países (Hahn, Lönnendonker e Schröder, 2008). Esse processo de formação da percepção do mundo, que é influenciado pelas coberturas internacionais, foi nomeado por Wilke (Wilke e Quandt, 1987, p. 8) como "construção da imagem". Os temas em pauta têm nesse contexto um papel importante como "elementos estruturais da imagem internacional midiática" (Hafez, 2002, p. 110). Quais temas ou assuntos, quais tipos de fatos e desenvolvimentos são selecionados pela mídia e classificados como dignos de publicação? Atribui-se às coberturas internacionais um forte efeito do chamado Agenda-Setting, já que geralmente falta ao público a experiência direta na região de cobertura. Assim, a mídia ganha cada vez mais influência sobre a criação de agendas temáticas (Hafez, 2002, p. 42). A associação entre coberturas internacionais e a construção de imagens culturais e nacionais é inegável (Prinz, 1970).

O termo "Imagem" foi cunhado por Boulding, um dos pioneiros da pesqui- sa de imagens na Alemanha (Boulding, 1961) como um conhecimento subjetivo da realidade, que surge por meio de instâncias de socialização e observação do meio. A formação da imagem auxilia o indivíduo a estruturar seu mundo exterior, e ela é tão marcante que ações políticas são determinadas não por fatos objetivos, mas sim pela imagem das situações (Boulding, 1959, p. 120). "It is what we think the world is like, not what it is really like, that determines our behaviour" (ibid.). Em outras palavras, o que determina a ação humana não é a realidade factícia, mas sim aquilo que nos aparenta como realidade. O termo imagem pode ser entendido como uma categoria geral, que engloba outros conceitos como estereótipo, preconceito ou imagem do inimigo (Hafez, 2002; Prinz, 1970). Assim, os efeitos de uma cobertura internacional não objetiva e tendenciosa não podem ser subestimados (Nafroth, 2002, p. 6), já que o modo como a mídia retrata uma nação irá influenciar profundamente como este país será percebido pelo público.

Por tais motivos, este artigo apresenta os resultados empíricos (Cazzamatta, 2014) em que a imagem do Brasil foi analisada na imprensa alemã entre os anos de 2010 a 2012. Somente no Brasil, há cerca de 1.400 empresas teuto-brasileiras. Além disso, o país é o principal parceiro econômico da Alemanha na América Latina (Auswärtiges Amt, 2013). Em 2009, a Alemanha também se tornou o quarto maior investidor do Brasil (Bandeira, 2011). O período selecionado visou integrar os meses que sucederam a visita de Lula à Alemanha em dezembro de 2009, a qual resultou em diversos acordos bilaterais (ibid.), assim como as eleições presidenciais de 2010 e as trocas de governos em 2011. 
Background teórico: Definição de coberturas internacionais

O papel das coberturas internacionais se tornou ainda mais importante no começo do século 21. Por conta da integração técnica, da expansão do networking político e das diversas formas de comunicação, as coberturas internacionais adquirem cada vez mais importância. Ou seja, em tempos de interação política e econômica em dimensões globais, é essencial para um país analisar se e de que forma ele recebe espaço e cobertura em outros sistemas midiáticos (Scherer et al., 2006, p. 201). A (não) percepção de uma determinada nação leva a formação de imagens específicas, que podem ter consequências concretas nos processos políticos e econômicos. O termo cobertura internacional entende-se como "conteúdos e processos da cobertura midiática sobre questões além do país de origem" (Hafez, 2005, p. 39). Trata-se de "comunicação jornalística mediada", que se diferencia de outras formas de comunicação que também ultrapassam as fronteiras nacionais, a exemplo da internet. Características típicas da cobertura jornalística internacional são: veiculação de programas redacionais específicos, seleção de informações e um grande alcance de público. Ou seja, determinantes que não necessariamente estão presentes na comunicação via internet, mesmo que esta ultrapasse as fronteiras nacionais (ibid.).

\section{Características estruturais e distorções em coberturas internacionais}

Um estudo do fluxo internacional de notícias realizado por Kim e Barnett (1996, p. 334) chegou à conclusão que as regiões mais isoladas do sistema interna- cional de informação correspondiam aos países menos desenvolvidos da África, Ásia, América do Sul e do antigo bloco soviético. O mesmo fenômeno também fora identificado anteriormente por (Meier, 1984, p. 219): “A América Latina, Europa Oriental e África estão entre as regiões jornalísticas mais invisíveis". Marcante para a controvérsia do desequilíbrio do fluxo de informações internacionais foi o trabalho da UNESCO no contexto da discussão para um "Novo Mundo de Informação e Ordem de Comunicação" (News World Information und Communication Order). Os países em desenvolvimento protestaram contra o domínio das agências de notícias e dos grandes meios de comunicação ocidentais (Hafez, 2002, p. 43) e apoiavam o argumento "radical" de que o equilíbrio e a liberdade do fluxo de informação se tratavam de um mito (Koschwitz, 1979, p. 466). As principais críticas da Comissão MacBrid, como ficou conhecido o estudo, apontam as seguintes falhas estruturais das coberturas internacionais: forte destaque a eventos irrelevantes; a associação de fatos desconexos; conclusões propositadamente falhas e problemáticas; construção da imagem do inimigo para legitimação de ações políticas e a não descrição de acontecimentos e problemas relevantes (Hafez, 2002 , p. 45). O fator "regionalismo" foi frequentemente detectado pela pesquisa. $\mathrm{Ou}$ seja, a maioria das notícias provinha de regiões vizinhas do país sob investigação. Constatou-se também uma orientação em torno das grandes metrópoles. Já em relação ao conteúdo, identificou-se uma parcela de notícias em quantidade desproporcional no campo da política. Além disso, com exceção dos sistemas de mídia do Leste Europeu, o conteúdo das notícias foi altamente caracterizado por matérias ne-
1- O programa para um Novo Mundo de Informação e Ordem de Comunicação (NWICO, da sigla em inglês) foi conduzido a pedido da UNESCO e consolidado pela comissão MacBride por meio do relatório "Many Voices On World - toward a new more just and more efficient world information and communication order".

O estudo conhecido como Foreign News Study foi realizado a partir da análise do noticiário de 29 países.

A interpretação dos dados foi conduzida por um time de pesquisadores de 13 nações diferentes e os resultados classificados conforme o sistema de mídia e nível de desenvolvimento do país em questão (Hafez, 2005, p.46). A amostra do estudo engloba os três ou quatro maiores jornais de cada país, que foram analisados durante o período de duas semanas (umas cronológica e uma falsa montada no prazo de 3 meses). Para o relatório completo acesse: http://unesdoc.unesco.org/ images/0006/000652/065257eo. 
gativas, principalmente aquelas provindas dos países do hemisfério sul, que atraem bem menos atenção da mídia internacional e, geralmente, aparecem associados à cobertura de crises e conflitos. Assim, fala-se em uma perspectiva conflituosa em que fatores negativos recebem a maior cota de atenção. Outro ponto levantado pelo estudo é o grande uso de agências de notícias como a principal fonte das coberturas internacionais. Por fim, a análise ressalta ainda características como a concentração de fontes provindas da elite, além da falta de contexto e ausência de problemas estruturais nas relações internacionais (Hafez, 2002, p. 45; Rullmann, 1996, p. 42).

\section{Influências sobre os mecanismos de seleção de notícias}

A descrita deformação das coberturas jornalísticas pode ser explicada parcialmente por meio dos critérios de seleção da notícia, abordados pelas teorias do valor da notícia e Gatekeeper. Em relação ao valor da notícia, Galtung und Ruge (1965) apresentaram doze fatores que geralmente afetam a escolha de acontecimentos. Os fatores como elitismo (em relação à nação ou pessoa), personalização e negativismo foram classificados como culturalmente dependentes. O pesquisador alemão Schulz (1976, p. 31-34) amplia em seu estudo o catálogo de fatores propostos por Galtung und Ruge, o que possibilita também a análise de notícias apolíticas e em contextos nacionais, além de elucidar com clareza modos de operacionalizar empiricamente os fatores noticiosos. O próximo passo decisivo no desenvolvimento da linha de pesquisa sobre o valor da notícia, de tradição europeia, foi o trabalho de Staab (1993) e a apresentação de um modelo final de seleção de notícias. Dessa forma, os fatores noticiosos podem ser, sob certas circunstâncias, instrumentalizados para legitimar uma decisão em relação a uma determinada escolha (Staab, 1990, p. 168). "É possível atribuir a um fato algumas características específicas" (ibid.). A questão decisiva para Staab (1993, p. 71) é se "a escolha jornalística deve ser vista como um total reflexo de características específicas de um fato (modelo causal) ou se esse padrão de escolha pode ser orientado de acordo com determinados interesses (modelo final)".

No entanto, somente a teoria do valor da notícia não basta para justificar os critérios de seleção jornalística que, como dito anteriormente, podem levar à deformação e distorção de uma cobertura internacional e, consequentemente, à formação de uma imagem equivocada de uma nação ou região. Diversos estudiosos da comunicação observaram que somente a teoria do valor da notícia é insuficiente para apreender os critérios de seleção jornalística. Staab (1993, p. 170) analisa: "A teoria da notícia não deve ser vista como uma teoria da seleção jornalística, mas sim como um modelo de análise e descrição da estrutura da realidade midiática”.

Assim como a teoria do valor da notícia, a perspectiva do Gatekeeper também analisa a seleção jornalística, mas o foco da abordagem recai principalmente sobre as preferências pessoais do repórter, sobre a influência das agências de notícias em relação ao conteúdo jornalístico ou até mesmo sobre a seleção e influência de editores e redatores (Stengel e Marschall, 2010, p. 117). A pergunta central nesse ponto está relacionada às funções do jornalista e das empresas de comunicação, que também influenciam a seleção e o conteúdo do material produzido (Kunczik e Zipfel, 2001, 
p. 117). A abordagem do Gatekeeper vê a mídia como um sistema social, em que notícias são selecionadas pelos comunicadores (Mükke, 2009, p.65). É postulado que a individualidade, preferência pessoal, interesses, opiniões, ideias e aversões dos jornalistas podem ser identificados no conteúdo e na seleção das notícias (ibid.). A teoria foi desenvolvida para apreender relações e circunstâncias mais complexas com base em estudos organizacionais $\mathrm{e}$ institucionais, que levam em consideração o processo da organização jornalística como um todo. Por esse viés, o jornalista não é visto como um indivíduo, mas sim como um integrante de uma burocracia dentro da produção de notícias (Mükke, 2009, p. 66). Jornalistas são seres culturais que pertencem não só a uma determinada cultura, mas também a uma subcultura profissional (Ginneken, 1998, p. 65). Ou seja, hierarquia dentro do sistema da redação e socialização profissional e política da organização também são fatores predominantes da seleção de notícias (Mükke, 2009, p. 66).

Schulz (1976) resume combinadamente as principais características de todas as etapas da evolução da teoria do Gatekeeper: 1) A seleção de notícias é parcialmente explicada por meio da experiência subjetiva, expectativa e opinião do jornalista; 2) O papel de coerção das redações e editoras deve ser considerado; 3) A seleção de notícias também é influenciada por chefes e colegas de profissão, além do conceito antecipado sobre o desejo do público, ideia normalmente errônea e pouco distinta (ibid.). 4) A linha editorial também é um fator importante e, por último, 5) o conteúdo das coberturas é altamente influenciado pelas agências internacionais de notícias e os jornalistas e chefes de redação se comportam passivamente frente a este material (Schulz, 1976, p. 11). Problemático nesta abordagem do Gatekeeper é que somente um dos aspectos acima apresentados costuma ser examinado empiricamente a cada estudo (ibid.). Além disso, a diferente atenção dada às notícias selecionadas e ao conteúdo em si das coberturas são fatores que ficam em segundo plano.

\section{Metodologia}

Para responder a pergunta - quais fatores determinam a cobertura internacional sobre o Brasil e qual imagem do país é produzida pela imprensa alemã, em outras palavras, quais frames são identificados no discurso sobre o Brasil? - foi utilizada uma combinação entre análise do conteúdo quantitativa e qualitativa. Entende-se como frame o processo descrito por (Entman, 1993, p. 52): "To frame is to select some aspects of a perceived reality and make them more salient in a communicating text, in such a way to promote a particular problem definition, causal interpretation, moral evaluation, and/or treatment recommendation for the item described". Para reconstruir a imagem do Brasil recorreu-se ao método quantitativo por dedução baseado nos trabalhos anteriores de Hafez (2002), Mükke (2009), Nafroth (2002), Richter e Gebauer (2010). Em seguida, fez-se uma análise qualitativa por indução de temas específicos da cobertura, de acordo com as normas propostas por Mayring (2010). Nessa etapa, procurou-se identificar os principais frames que marcam a imagem brasileira. O manual de codificação com suas instruções de análise quantitativas e qualitativas está especificado em Cazzamatta (2014, p. 237-251).

O corpus da pesquisa foi formado por 431 artigos em que a palavra Brasil - ou 
termos relacionados ao país - aparecesse no título ou subtítulo do texto. Com essa decisão, visou-se selecionar o maior número de artigos em que o Brasil fosse o foco principal da pauta. Os jornais que compuseram o material são os de grande circulação da imprensa alemã de qualidade. Estes veículos, de alcance nacional, são considerados importantes formadores de opinião e se diferenciam da imprensa regional ou popular como o jornal Bild (Bieber, 2011, p. 71; Hafez, 2002, p. 32; Kollmorgen e Hans, 2011, p. 141; Nafroth, 2002, p. 92-93). São eles: Süddeutsche Zeitung (SZ), liberal, amplamente politizado e intelectual; Frankfurter Allgemeine Zeitung (FAZ), economicamente liberal e politicamente conservador; Die Welt (conservador de direita) e, por fim, o tageszeitung (taz), alternativo e de esquerda. Também foram considerados os semanários Der Spiegel (liberal de esquerda e orientação crítica ao sistema), Focus, Die Zeit (liberal de esquerda) e, por último, a ilustrada Stern.

\section{Resultados quantitativos}

A primeira hipótese, de que a cobertura internacional sobre o Brasil é marcada por fatos pontuais, descontínuos e de curta duração, foi confirmada. Os temas relacionados ao meio ambiente, que foram acompanhados principalmente pelos jornais SZ e taz ao longo dos três anos, representam uma exceção. Em geral, a hipótese dos autores noruegueses Galtung e Ruge (1965) parece se confirmar no caso da cobertura do Brasil - quanto mais bem delineado, claro e curto for um acontecimento, maior seu valor noticioso. No entanto, para a cobertura relacionada ao meio ambiente, em sível. Segundo o autor alemão, temas inseridos há um longo tempo no noticiário já ultrapassaram a barreira seletiva e chamam a atenção dos jornalistas, como, por exemplo, o desmatamento da Amazônia. Por essa razão, tais assuntos encontram um espaço especial na mídia.

O trabalho empírico também constatou que a seleção temática para a cobertura brasileira não segue, pelo menos dentro da Alemanha, os padrões de outras coberturas internacionais, como no caso da África ou do Oriente Médio, em que o domínio de temas políticos pode ocupar até $50 \%$ de toda a cobertura de uma região. Mesmo que a comparação com outros estudos seja complicada por conta da diversidade metodológica das análises, a hipótese da centralização política não foi confirmada. O tema Política Interna corresponde a $15,6 \%$ de toda a cobertura. Outros temas como Meio Ambiente (15,9\%) e Economia (18,5\%) substituíram o tradicional domínio da política, sempre constatado em estudos anteriores do gênero. Outras áreas de cobertura também receberam mais atenção quando comparadas às outras regiões do planeta como Cultura e Sociedade $(9,8 \%)$, Interesse Humano (8,3\%) e Social $(6,5 \%)$. Esta tendência não corresponde aos estudos anteriores de nações do terceiro mundo ou da América do Sul. Por exemplo, uma análise midiática realizada pelo Ministério Alemão para o Trabalho Conjunto e Desenvolvimento Econômi$\mathrm{CO}^{2}$, de 1983, observa a tendência das coberturas internacionais concentrarem-se nas seções de política (54\%), economia (13\%) e catástrofe (17\%). A preferência temática entre os jornais também é bastante clara: enquanto no taz predominam temas relacionados ao meio ambiente, o FAZ cobre muito mais economia. Já o Die Welt se 
interessa bastante por política externa e economia, enquanto o Die Zeit por economia e meio ambiente. Por fim, o $S Z$ e a Der Spiegel têm um bom equilíbrio de temas.

$\mathrm{O}$ pequeno percentual de temas políticos $(15,6 \%)$ talvez explique a falta de contexto de algumas matérias ou a visão pouco crítica em relação ao crescimento do país e sua distribuição de renda. Temas cruciais da política brasileira, como as reformas sociais restritas pelo capital e a falta de mudança de fatores estruturais, que permitem cada vez mais as desigualdades e concentração de renda no país (Marques e Mendes, 2007), não aparecem no noticiário alemão. Alianças políticas duvidosas, conflitos entre o governo e seu próprio partido, oposição e mídia também não são temas abordados dentro da grande área classificada como política. A imprensa busca fatores noticiosos específicos como acontecimentos claros e contornáveis em um curto espaço de tempo, o que explica a falta de pano de fundo e contexto nas reportagens.

No caso da política externa, prevalecem as relações internacionais entre Brasil e Alemanha com um tom altamente econômico. Esse mesmo resultado foi constatado em um estudo sobre a cobertura da China na Alemanha (Richter e Gebauer, 2010), o que pode indicar uma tendência específica para a cobertura de países emergentes. A diversificação da política externa brasileira, por outro lado, recebeu pouca atenção no noticiário. Praticamente não houve textos sobre as cooperações Sul-Sul. As relações do Brasil com a União Europeia ou com os Estados Unidos também foram pouco abordadas. A imprensa acompanha majoritariamente os interesses comerciais entre Brasil e Alemanha, sem tratar necessariamente das estratégias da política ex- terna brasileira.

$\mathrm{Na}$ seção de economia, praticamente metade das reportagens do setor (49\%) retrata o Brasil como local de produção, mercado para produtos e serviços alemães ou como possibilidade para novos investimentos e expansão comercial. A imprensa acompanha a agenda das empresas e corporações e o relacionamento econômico entre ambos os países. Aqui se encontram fatores noticiosos como relevância e etnocentrismo. Dentro da seção economia, $31,9 \%$ das matérias têm um envolvimento alemão nos acontecimentos que motivaram a pauta. Uma explicação para o domínio econômico da cobertura jornalística sobre o Brasil na Alemanha pode ser o crescimento das relações bilaterais. A visita do ex-presidente Lula, em dezembro de 2009, resultou em diversos acordos entre os dois países. Em agosto de 2010, o ministério de assuntos estrangeiros da Alemanha divulgou o Novo Plano para a Política da America Latina (Auswärtiges Amt, 2010) e reforçou ainda mais as relações bilaterais (Bandeira, 2011). O ex-ministro das relações exteriores da Alemanha, Guido Westerwelle, declarou em 2010, durante sua viagem pelo continente: "será uma preocupação central do meu governo abrir portas para as empresas alemãs" (Süddeutsche Zeitung, 2010). A hipótese de Schenk (1987, p. 51), pelo menos na seção de economia, parece se confirmar: entre as variáveis que influenciam consideravelmente o fluxo de notícias internacionais constam majoritariamente os interesses econômicos e de política externa entre os Estados. Parece que a importância de um país para a economia alemã ou ocidental é fundamental para chamar a atenção da mídia nesse setor (Hafez, 2002, p. 298).
3- "Es wird ein Kernanliegen meiner Außenpolitik sein, Türen zu öffnen für Deutsche

Unternehmungen (SZ, 10.03.2010) 
A incomum presença de temas do meio ambiente $(15,9 \%)$ aborda questões como a construção da usina em Belo Monte (4,9\% de toda a cobertura sobre o Brasil), a liberação de financiamento para a usina nuclear Angra 3 no Rio de Janeiro (3,5\%), a tentativa do parlamento brasileiro em flexibilizar o código florestal (3\%) e os danos ambientais da empresa ThyssenKrrupp também no Rio de Janeiro (1,9\%). A preferência por temas ambientais não é só constatada pela análise do conteúdo do noticiário. Correspondentes da região também relatam a alta demanda das redações alemãs pelo tema, principalmente em relação aos conflitos na região da Amazônia (Wienand, 2008, p. 330). Fatores noticiosos como prejuízo, catástrofe, conflito, criminalidade e envolvimento alemão são constatados nessa etapa da análise. Assim, a hipótese da adição de (Galtung e Ruge, 1965) faz sentido: quanto mais fatores noticiosos recaírem sobre um acontecimento, maior a probabilidade de o fato encontrar espaço na imprensa (Schulz, 1976, p. 19). Porém, enquanto o Brasil possui uma imagem bastante positiva e de sucesso no noticiário econômico, a situação é bastante diferente na cobertura ambiental. Nesta seção temática prevalecem tensões entre o crescimento econômico a qualquer custo e as políticas ambientais.

Em comparação às áreas como meio ambiente ou economia, o noticiário alemão sobre o Brasil dedica menos espaço aos temas sociais $(6,5 \%$ de toda a cobertura). Essa abordagem é mais importante para os jornais taz (13,5\% da cobertura dentro do veículo), Der Spiegel (15,4\%) e SZ (7\%). A ocupação das favelas brasileiras pelas Unidades de Polícia Pacificadora (UPPs) foi bastante elogiada pela imprensa alemã.
Por outro lado, temas como a violência policial, a corrupção dentro da organização ou a péssima condição carcerária não foram retratados. Também foram pouco exploradas as questões do racismo na sociedade brasileira. Já a área temática Cultura e Sociedade tem uma grande variedade de assuntos, de literatura, arquitetura, música, teatro, até mídia, religião e carnaval. No entanto, os temas são bastante pontuais e nenhum assunto específico é acompanhado pela imprensa com continuidade. A preferência nesta área recai sobre o Brasil como destino de viagem, responsável por $28 \%$ dos artigos dentro da área Cultura e Sociedade.

Durante a análise dos temas, a perspectiva da notícia foi codificada e classificada em três possíveis categorias: (1) "foreign news abroad", (2) "foreign news at home" e (3) "home news abroad" (Hafez, 2002). No primeiro caso, tratam-se de notícias sobre o Brasil, ocorridas no Brasil, sem nenhum envolvimento alemão. A segunda categoria, por sua vez, descreve notícias sobre o Brasil que ocorreram na Alemanha, como, por exemplo, a apresentação de um músico brasileiro em Berlim. Por fim, a terceira categoria descreve um fato noticioso sobre a Alemanha, que ocorreu no Brasil. Por exemplo, as atividades da empresa ThyssenKrrupp no Rio de Janeiro. No caso da seção de Cultura e Sociedade, encontrou-se o maior grau de "foreign news at home" (22\% dentro da área de cobertura). Mesmo na área de política externa, em que há muitas visitas de oficiais brasileiros na Alemanha, esse percentual foi de 9,6\%.

A imprensa acompanha fatos específicos como apresentações de artistas na Alemanha e compilações musicais. Por outro lado, temas como literatura, arquitetura 
ou teatro aparecem geralmente quando há um envolvimento alemão ou europeu no lançamento de algum produto cultural.

\section{Retrato das elites}

Para averiguar o equilíbrio das fontes, foi realizada uma análise quantitativa operacionalizada por três categorias baseadas em estudos anteriores (Hafez, 2002): 1) Fontes oficiais do governo; 2) grupos sociais organizados como igrejas, bancos, corporações, oposição, universidades, ONGs e empresas e 3) grupos sociais não organizados como os cidadãos comuns. Foram codificadas até três fontes por texto em um total de 431 matérias. Apesar do domínio de temas políticos não ter sido constatado, como no caso de outras regiões do globo, representantes oficiais do governo aparecem com muito mais frequência como fonte ou ator da notícia, com um percentual de 40,2\%. Assim, a hipótese do domínio das elites políticas na cobertura foi confirmada. Essas fontes prevalecem principalmente nos temas relacionados à política interna e externa, além de meio ambiente. Nesse caso, a afirmação de Galtung e Ruge de 1965 é reforçada (Schulz, 1976, p. 20): "quanto mais distante for uma nação, mais forte é a tendência do noticiário internacional de retratar as ações da elite deste país". Depois das fontes oficiais do governo, os grupos sociais organizados como ONGs e corporações são os que encontram um espaço maior no noticiário alemão sobre o Brasil, com um percentual de 25,3\%. Esse tipo de fonte está bastante presente nas coberturas sobre economia e meio ambiente, uma vez que nessas áreas a presença de ONGs e organizações financeiras possui um papel importante. Embora não se tratem de fontes oficiais, a tendência do elitismo se mantém, uma vez que estão em foco grupos sociais organizados como grandes corporações ou até mesmo a oposição.

Nesse aspecto também pôde ser constatado um grau de etnocentrismo uma vez que as fontes classificadas como grupos sociais organizados da Alemanha estiveram levemente mais presentes que as brasileiras $(37,8 \%$ contra $34,7 \%)$. Os grupos não-organizados - que podem ser entendidos como as pessoas comuns representam, no caso da cobertura sobre o Brasil, somente $18,4 \%$ das fontes.

\section{Negativismo e etnocentrismo em pauta}

Ao analisar toda a cobertura, não é possível afirmar que a imagem do Brasil na Alemanha é marcada pelo negativismo, uma vez que, no geral, $38,1 \%$ das matérias analisadas foram negativas, 32,9\% positivas e $29,0 \%$ neutras. Para operacionalizar essa análise, classificou-se não o tom da matéria, mas o fato reportado. Como acontecimentos negativos constam casos de corrupção, destruição ambiental, criminalidade, racismo e conflito. Entre os fatos positivos estão reportagens sobre o crescimento econômico, desenvolvimento, construção de novas relações bilaterais, otimismo do mercado e novos projetos. Como neutros foram classificados eventos como conferências, balanços, descrição de índices da bolsa e assim por diante.

Apesar dos fatos negativos terem um percentual levemente maior, ainda assim há um certo equilíbrio. Uma cobertura de cunho conflituoso é classificada na literatura quando os fatos negativos ultrapassam os 50\%. (Hafez, 2002). No entanto, ao analisar a categoria de temas separadamente, o negativismo da cobertura em áreas específicas é bastante claro. Aconte- 
cimentos negativos são predominantes nas seções de Meio Ambiente (91,4\%) e Social $(72,7 \%)$. Jornais que concentram suas coberturas sobre o Brasil nos temas ambientais, como o taz e o $S Z$, têm, consequentemente, um tom mais negativo. Por outro lado, temas como Política Interna (25,6\% positivo e 50\% neutro), Política Externa (51,9\% positivo e $34,6 \%$ neutro) e Economia e Finanças (40,4 positivo e $45,7 \%$ neutro) tiveram um saldo bastante positivo.

Além disso, um quarto de toda a cobertura foi marcado por um envolvimento alemão na pauta, principalmente nos temas de política externa (38,5\%), economia $(31,9 \%)$ e meio ambiente $(34,6 \%)$. Apesar do fator auto-identificação ou etnocentrismo estar presente, o percentual é muito menor se comparado a outras regiões do mundo como a África (Mükke, 2009, p. 130-132). Como o autor constata, se o país onde a cobertura é produzida estiver envolvido no fato, então esse envolvimento funciona como um catalisador para a seleção da notícia (Mükke, 2009, p. 78). Por fim, a maioria dos textos é proveniente de correspondentes com base no Brasil (taz e Spiegel) ou em outras cidades da América do Sul a exemplo de Buenos Aires (SZ e $F A Z$ ), o que pode explicar a grande variedade de temas retratados. Ao contrário do esperado, as agências de notícias têm um papel menor na cobertura, sendo responsáveis por apenas 3,5\% das matérias. Atores externos, especialistas e intelectuais também não estão muito presentes - somente uma porcentagem de 2,5\%. Nesse ponto, uma possível influência das agências de notícias nas redações alemãs e no relacionamento com seus correspondentes não pôde ser verificada empiricamente, uma vez que por falta de recursos não foi possível operacionalizar um questionário com jornalistas.

\section{Resultados qualitativos: a imagem dual do Brasil}

Os temas mais frequentes na imprensa alemã, identificados a partir de dados quantitativos, foram submetidos a uma análise qualitativa. São eles: (1) a construção da usina em Belo Monte, (2) a flexibilização do código florestal, (3) o financiamento alemão para Angra 3 e (4) o sucesso econômico brasileiro. Entre os principais frames associados à imagem brasileira está a combinação da prioridade do crescimento econômico com a pouca consciência ecológica. Diversos textos da imprensa alemã transportam a ideia do crescimento econômico a qualquer custo, sem levar em consideração o meio ambiente ou as minorias sociais. "Provavelmente o presidente mais popular do mundo está entusiasmado com turbinas poderosas, elas são para ele o impulso decisivo para a ascensão do Brasil ao poder econômico" (Burghardt, 2010). Para a imprensa alemã parece que crescimento econômico e proteção ambiental não podem coexistir (Fatheuer, 2012, p. 87).

No caso específico da construção da usina Belo Monte, não foi retratado pela imprensa alemã, por exemplo, que o projeto tornou-se bem menos agressivo em comparação aos tempos da ditadura militar. As grandes usinas foram deixadas de lado, as turbinas serão acionadas pelo curso natural do rio e 500 quilômetros quadrados em vez de 18 mil serão inundados na versão atual da proposta (Quero, 2010; The Economist, 2013). Nesse ponto da análise, pode-se identificar uma falta de contexto, uma vez que a perspectiva histórica do projeto é ignorada. Não se trata de negar os impac- 
tos ecológicos causados pela construção da usina, mas sim de tratar o desenvolvimento sustentável em uma perspectiva internacional. É somente no Brasil que "o crescimento econômico e o interesse das indústrias são, na dúvida, mais importantes que as árvores?" (Burghardt, 2012). A imprensa alemã cumpre seu papel como observadora crítica, questiona os impactos ambientais, as ameaças aos ativistas do meio ambiente e o descaso em relação às minorias, mas o frame do crescimento a qualquer custo nunca é relativizado. Além disso, toda discussão relacionada ao meio ambiente é altamente polarizada entre fontes do governo e organizações não governamentais. A imprensa, por um lado, dá voz aos povos indígenas que serão prejudicados pelo projeto, mas não há declarações dos trabalhadores da cidade de Altamira ou qualquer outra opinião sobre a possibilidade de geração de empregos.

Essa tendência de centralizar o noticiário em torno das elites, em que grupos sociais organizados encontram grande espaço na mídia, foi verificada também no exemplo da flexibilização do código florestal. A discussão novamente se polarizou em torno do lobby da indústria agrária e das ONGs ambientalistas. No entanto, representantes do Movimento dos Sem Terra (MST), por exemplo, não foram escutados. A falta de contexto, nesse exemplo, também foi identificada. Houve uma parcela de camponeses que, mesmo desejando maior interação entre meio ambiente e política agrária, apoiou parcialmente as reformas no código florestal, com algumas restrições, para facilitar a vida do pequeno agricultor (Repórter Brasil, 2011). Não chegou ao conhecimento da imprensa alemã que até mesmo as diversas organizações de trabalhadores da terra e ONGs divergiam entre si sobre como a reforma deveria ser conduzida.

No exemplo que envolve a política nuclear do país e a construção de Angra 3, o Brasil é marcado pela irresponsabilidade e pela falta de seriedade e confiança. $\mathrm{O}$ tema foi acompanhado somente pelo taz e é possível constatar novamente a falta de contexto e a apresentação de fatos desconexos. Três argumentos principais são questionados pela imprensa alemã em relação à política atômica brasileira: a) a falta de segurança em Angra 3, de acordo com os padrões internacionais; b) a negação do Brasil em assinar o protocolo adicional do Tratado de Não-Proliferação Nuclear e c) a simpatia do governo brasileiro em relação ao Irã. Além disso, a postura do governo alemão também foi altamente criticada. A imprensa colocou como uma grande contradição a Alemanha planejar fechar suas usinas nucleares no país e fornecer crédito para outras nações construírem suas usinas. Todos esses pontos colocados pela imprensa alemã, inclusive a falta de preocupação brasileira com as normas de segurança, argumentavam contra Angra 3. O que não é nem de longe abordado pela imprensa é a questão diplomática em torno da discussão nuclear. O Brasil possui grandes reservas de urânio e domina todo o ciclo do enriquecimento do mineral e, desse modo, tenta discutir o direito do país ao uso da energia nuclear de modo pacífico, além de problematizar o desarmamento nuclear das grandes potências mundiais (Guimarães, 2010). O problema do oligopólio nuclear não é sequer abordado na imprensa alemã. Também foi bastante sugerido pelos meios de comunicação alemães que o Brasil não assinava o tratado adicional por medo dos rígidos padrões de segurança. E, dessa forma, a Alemanha 
não deveria liberar o crédito. No entanto, a natureza desigual de tal protocolo não foi trazida à luz da discussão. Não foi colocado em cheque a natureza do acordo ou sua central premissa, ou seja, o próprio desarmamento das potências nucleares.

No entanto, enquanto a imagem do país é marcada pelo tom negativo na cobertura sobre meio ambiente, o quadro é bem diferente nas seções de economia e política. A hipótese que a imagem brasileira é excessivamente positiva nessa área temática foi confirmada. Enquanto nas seções de finanças e política o crescimento do país é altamente elogiado, na cobertura do meio ambiente é exatamente esse crescimento que é responsabilizado pelos impactos ambientais. A posição crítica da imprensa alemã em relação ao meio ambiente é inexistente na cobertura política. Crescimento econômico, programas sociais e de distribuição de renda aparecem como a marca do sucesso brasileiro. Porém, o modelo de desenvolvimento do país não é discutido de nenhuma forma. Enquanto a imprensa alemã elogia a ascensão de 20 milhões de pessoas à classe média, Marcio Pochmann, economista e presidente do IPEA, compara o país com uma sociedade feudal, principalmente por suas desigualdades (Pochmann, 2010). O fato do Brasil não ter realizado durante os anos de governo Lula, supostamente com tendências de esquerda, nenhuma reforma agrária, tributária ou social não parece ter grande importância para a imprensa alemã. Assim como o fato de os ricos majoritariamente se beneficiarem da política financeira do país também não parece digno de questionamento. Além disso, a ideia que o Brasil passará o Reino Unido economicamente é transportada o tempo todo pelos jornais e revistas. O que não é apresentado é a dife- rença da renda per capita (US\$ 8.300 do Brasil contra US\$ 43.700 do Reino Unido). O desenvolvimento social ainda necessário para poder se comparar com a Inglaterra não é um assunto abordado dentro da retratada euforia econômica. Até mesmo a definição de classe média, criticada por diversos pesquisadores (Anderson, 2011; Mattei, 2012), não é questionada. Ao contrário da imprensa alemã, Anderson fala no surgimento de uma "pobre classe trabalhadora" e não de uma nova classe média.

Além disso, também não foi relativizado pela imprensa alemã que embora o programa Bolsa Família realmente seja um grande sucesso, trata-se somente de um programa de governo (Marques e Mendes, 2007). O direito a uma renda mínima não está garantido ou ancorado na constituição brasileira e pode ser a qualquer momento suspendido por outro partido. Por fim, constatou-se um exagero na exaltação do sucesso brasileiro, uma vez que o país, apesar de apresentar melhoras significativas, ainda precisa realizar importantes reformas de base, como apontam diversos pesquisadores. Assim, não é de se surpreender que Anderson (2011), diferentemente da imprensa alemã, retrate um Brasil de "progresso sem conflito" e de "distribuição sem redistribuição".

\section{Conclusão}

Como mostrou o estudo conduzido com base nos 431 textos, de 2010 a 2012, a imagem do Brasil na imprensa alemã apresenta duas facetas opostas - uma extremamente negativa em relação ao meio ambiente e outra exageradamente positiva quando se trata de crescimento econômico e programas sociais. A maioria dos acontecimentos é pontual e de fácil delimitação, 
com exceção dos temas de meio ambiente, que são acompanhados com grande interesse. Como constatado em estudos anteriores de coberturas internacionais, as principais fontes e atores do noticiário se concentram em figuras oficiais do governo, grandes corporações e ONGs. Pessoas comuns encontram menos espaço no noticiário alemão. Ao contrário de outras regiões do globo, a cobertura sobre o Bra- sil não se concentra majoritariamente em torno de temas políticos e apresenta vasta palheta de assuntos. A carência de profundidade na cobertura política pode indicar porque o público alemão reagiu de modo tão surpreso aos protestos que eclodiram no Brasil em julho de 2013, afinal a imagem positiva do sucesso econômico do país não condizia com os novos acontecimentos.

\section{Referências bibliográficas}

ANDERSON, P. Lula's Brazil. London Review of Books, v. 33, n. 7, p. 3-12, 31 mar. 2011. AUSWÄRTIGES AMT. Deutschland, Lateinamerika und die Karibik: Konzept der Bundesregierung. [s.l.] Auswärtiges Amt, 2010. Disponível em: <http://www.auswaertiges-amt.de/cae/servlet/contentblob/367294/publicationFile/93979/LAK-Konzept.pdf>. BANDEIRA, M. O milagre alemão e o desenvolvimento do Brasil (1949-2011). 2a. ed. rev. e ampliada ed. São Paulo, SP: Editora Unesp, 2011.

BIEBER, L. China in der deutschen Berichterstattung 2008: eine multiperspektivische Inhaltsanalyse. 1. Auflage ed. Wiesbaden: VS Verlag für Sozialwissenschaften, 2011.

BOULDING, K. E. National Images and International Systems. The Journal of Conflict Resolution, v. 3, n. 2, p. 120-131, jun. 1959.

BOULDING, K. E. The image: knowledge in life and society. Ann Arbor: University of Michigan Press, 1961.

BURGHARDT, P. Trotz aller Liebe. Süddeutsche Zeitung, 13 out. 2010.

. Leises Machtwort. Süddeutsche Zeitung, 29 maio 2012.

CAZZAMATTA, R. Brasilien-Berichterstattung in der deutschen Presse. Berlin: Frank \& Timme, 2014.

ENTMAN, R. M. Framing: Toward Clarification of a Fractured Paradigm. Journal of Communication, v. 43, n. 4, p. 51-58, dez. 1993.

FATHEUER, T. The Amazon Basin. A Paradigmatic Region Between destruction, Valorisation, and resistance. In: HEINRICH-BÖLL-STIFTUNG (Ed.). Inside a Champion. An Analysis of the Brazilian Development Model. Berlin: Heinrich-Böll-Stiftung, 2012. p. 75-88.

GALTUNG, J.; RUGE, M. H. The Structure of Foreign News: The Presentation of the Congo, Cuba and Cyprus Crises in Four Norwegian Newspapers. Journal of Peace Research, v. 2, n. 1, p. 64-90, 1 jan. 1965.

GINNEKEN, J. VAN. Understanding global news: a critical introduction. London; Thousand Oaks: Sage, 1998.

GUIMARÃES, S. P. A Energia Nuclear e a Soberania Nacional. Carta Maior, 5 abr. 2010. 
HAFEZ, K. Die politische Dimension der Auslandsberichterstattung. 1. Aufl ed. Baden-Baden: Nomos, 2002.

_. Mythos Globalisierung: warum die Medien nicht grenzenlos sind. 1. Aufl ed. Wiesbaden: VS Verlag für Sozialwissenschaften, 2005.

HAHN, O.; LÖNNENDONKER, J.; SCHRÖDER, R. (EDS.). Deutsche Auslandskorrespondenten: ein Handbuch. Konstanz: UVk Verlagsgesellschaft, 2008.

KIM, K.; BARNETT, G. A. The Determinants of International News Flow: A Network Analysis. Communication Research, v. 23, n. 3, p. 323-352, 1 jun. 1996.

KOLLMORGEN, R.; HANS, T. Der verlorene Osten. In: KOLLMORGEN, R.; KOCH, F. T.; DIENEL, H.-L. (Eds.). Diskurse der deutschen Einheit: Kritik und Alternativen. Wiesbaden: VS Verlag für Sozialwissenschaften, 2011. p. 323-352.

KOSCHWITZ, H. Internationale Publizistik und Massenkommunikation. Aufriss historischer Entwicklungslinien und gegenwärtiger Trends. Publizistik, v. 24, p. 458-483, 1979.

KUNCZIK, M.; ZIPFEL, A. Publizistik: ein Studienhandbuch. Köln: Böhlau, 2001.

MARQUES, R. M.; MENDES, A. Servindo a dois senhores: as políticas sociais no governo Lula. Rev. Katál. Florianópolis, v. 10, n. 1, p. 15-23, jun. 2007.

MATTEI, L. Brasilien Development at the Beginning of the 21st Century. Economic Growth, Income Distribution, and Environmental Destruction. In: HEINRICH-BÖLLSTIFTUNG (Ed.). Inside a Champion. An Analysis of the Brazilian Development Model. Berlin: Heinrich-Böll-Stiftung, 2012. p. 31-44.

MAYRING, P. Qualitative Inhaltsanalyse Grundlagen und Techniken. Weinheim: Beltz, 2010.

MEIER, W. A. Ungleicher Nachrichtenaustausch und fragmentarische Weltbilder: eine empirische Studie über Strukturmerkmale in der Auslandberichterstattung. Bern; New York: P. Lang, 1984.

MÜKKE, L. "Journalisten der Finsternis": Akteure, Strukturen und Potenziale deutscher Afrika-Berichterstattung. Köln: Von Halem, 2009.

NAFROTH, K. Zur Konstruktion von Nationenbildern in der Auslandsberichterstattung: das Japanbild der deutschen Medien im Wandel. Münster: Lit, 2002.

POCHMANN, M. A Desigualdade no Brasil é coisa de Sociedade Feudal, agosto 2010. Disponível em: <http://issuu.com/carosamigos/docs/pdfs_ca_161leitor>

PRINZ, G. Heterostereotype durch Massenkommunikation. Publizistik, v. 15, p. 195210, 1970.

QUERO, C. Entenda a polêmica envolvendo a usina de Belo Monte. BBC Brasil, 20 abr. 2010.

REPÓRTER BRASIL. O avanço da soja e o Novo Código Florestal Uma análise dos impactos do projeto em debate no Congresso. [s.l.] Repórter Brasil, Agosto 2011. Disponível em: <http://reporterbrasil.org.br/documentos/Soja2011.pdf>. Acesso em: 20 jun. 2014.

RICHTER, C.; GEBAUER, S., HEBERER, THOMAS. Die China-Berichterstattung in den deutschen Medien. Berlin: Heinrich-Böll-Stiftung, 2010.

RULLMANN, A. Modernisierung und Dependenz. Paradigmen internationaler Kom- 
munikationsforschung. In: Internationale Kommunikation: eine Einführung. Opladen: Westdt. Verl., 1996. .

SCHENK, B. Die Struktur des internationalen Nachrichtenflusses: Analyse der empirischen Studien. Rundfunk und Fernsehen, v. 35, n. 1, p. 36-54, 1987.

SCHERER, H. et al. So nah und doch so fern? Zur Rolle des Nachrichtenfaktors "Nähe" in der internationalen Tagespresse. Publizistik, v. 51, p. 201-224, 2006.

SCHULZ, W. Die Konstruktion von Realität in den Nachrichtenmedien: e. Analyse d. aktuellen Berichterstattung. 1. Aufl ed. Freiburg [Breisgau] ; München: Alber, 1976.

STAAB, J. F. Nachrichtenwert-Theorie: formale Struktur und empirischer Gehalt. Freiburg [im Breisgau]: K. Alber, 1990.

. Entwicklung der Nachrichtenwert-Theorie. Theoretische Konzepte und empirische Überprüfung. In: WILKE, JÜRGEN (Ed.). Fortschritte der Publizistikwissenschaft. Freiburg [Breisgau] ; München: [s.n.]. .

STENGEL, K.; MARSCHALL, J. Verwandte und konkurrierende Ansätze. In: PATRICK, R.; HANS-BERND, B. (Eds.). Nachrichtenwerttheorie. Baden-Baden: Nomos, 2010. p. $116-131$.

SÜDDEUTSCHE ZEITUNG. Rohr schlägt Rübe. 3 out. 2010.

THE ECONOMIST. The rights and wrongs of Belo Monte. 5 abr. 2013.

WIENAND, J. Mehr als Samba, Drogen und Che Guevara - Das Berichtsgebiet Südamerika. In: Deutsche Auslandskorrespondenten : ein Handbuch. Konstanz: UVk Verlagsgesellschaft, 2008. p. 323-336.

WILKE, J.; QUANDT, S. (EDS.). Deutschland und Lateinamerika: Imagebildung und Informationslage. Frankfurt/Main: K.D. Vervuert, 1987.

Estudos em Jornalismo e Mídia está sob a Licença Creative Commons 2.5 